\title{
Política e produção de subjetividade: música e literatura
}

Pedro Dolabela Chagas

Recebido em 30/05/2011 - Aprovado em 30/08/2011

\section{Resumo}

O artigo versa sobre as condições contemporâneas da relação entre política e produção de subjetividade na música ena literatura, sob dois ângulos precisos: 1) as diferenças entre os tipos de experiência estética que as duas artes favorecem; 2) a atualização destas experiências nas condições atuais de disseminação social da arte. A partir da contribuição de autores dos Estudos Literários (Zumthor, Iser, Gumbrecht) e da filosofia (Deleuze, Guattari, Lipovetski), entre outros campos, debate-se o contraste entre a sensorialidade da música o o estímulo da literatura à interpretação, depreendendo-se dele 1) as razões das diferenças entre a disseminação social de umae de outra; 2) as diferenças entre a música e a literatura como instâncias de produção de subjetividade. Neste último item, descreve-se a música como uma força que subjetiva o indivíduo ao "arrastá-lo" (à revelia do seu controle consciente) a uma posição diferenciada, ao passo que a literatura estimula a vivência de realidades alternativas ao cotidiano vivido. Na afirmação da legitimidade destes dois processos de subjetivação, resgata-se a experiência estética sensorial da crítica moral a que ela foi historicamente submetida, ao delimitar-se, para ela assim como para a experiência de cunho interpretativo, lugares politicamente produtivos dentro das condiçôes atuais (democráticas) de circulação de informação. Como objetivo geral, almeja-se, a partir da comparação de cunho tipológico entre as duas artes, o estabelecimento de um referencial analítico descritivo para a observação das suas presenças e posições relativas na sociedade contemporânea.

Palavras-chave: literatura; música; política; subjetividade; experiência estética. 
Num livro de lançamento recente, o historiador Tim Blanning (2011) afirma que a música predomina socialmente, hoje, sobre as demais artes. Com isso, ele não está se referindo a algum tipo de música em particular, mas à música enquanto tal, cujo "triunfo" ele avalia a partir de um conjunto de dados empíricos. Tais dados correspondem ao aumento gradativo do prestígio social dos músicos (das suas posições subalternas nas cortes européias do século XVIII às fortunas adquiridas pelos astros do rock), à mudança de propósito e função social da música (da sua submissão à religião e à nobreza à sua autonomia autoral), à evolução dos seus lugares de apresentação (da execução em ambientes não produzidos para ela - como as igrejas e os salões dos palácios -, passando pela construção dos seus ambientes próprios - as óperas e salas de concerto - até a sua conquista de espaços alheios - como os estádios esportivos), à evolução tecnológica (que a tornaria onipresente na era da reprodução eletrônica) e à sua atuação em eventos políticos e sociais relevantes (como as guerras nacionalistas da Europa e o movimento racial americano dos anos 60). Ao passo que os dois primeiros itens não podem ser circunscritos à música, os três últimos são nela mais predominantes.

Blanning não estabelece distinção entre as diferentes formas musicais: a assertiva do seu "triunfo" vem da ampla disseminação social da música, que - em sua força sensual, a-racional, "contagiosa" - se tornou onipresente com as novas tecnologias de armazenamento e reprodução. Enquanto isso (e em que pese o caráter quase "coletivo" da recepção de tantos best-sellers), a literatura é mais restrita a um domínio individual de experiência: o seu contraste com a disseminação incontrolável da música parece decidir o seu destino; mesmo um best-seller não se propaga tão extensamente quanto uma canção de sucesso. Neste artigo, associaremos a onipresença da música à sua capacidade de arrastar o ouvinte, de carregá-lo de forma não-consciente e nãocontrolada a estados imprevistos. Disso derivaremos uma apreciação conceitual das diferenças entre a música e a literatura, observando as suas propriedades imanentes e os seus impactos de larga escala. Trataremos o "arrastar" da música como uma instância de formação de subjetividade, demarcando a sua diferença em relação à demanda pela interpretação que caracteriza o texto literário - o que ajudará a fundamentar as diferenças entre a literatura e a música, apreciando as possibilidades de uma e outra como instâncias de produção de subjetividade (no componente político que isso pode assumir). Decerto tais distinções são de cunho tipológico: não há características que se possa considerar "essenciais" a cada uma das artes e comuns a todas as suas produções. O próprio contraste entre a sensorialidade da música e a interpretação da literatura não é absoluto; no momento adequado, veremos que certa semântica perpassa 
a sensorialidade. Ainda assim, o reforço maior de uma e outra a um e outro tipo de experiência nos parece consistente o bastante para derivar, dele, uma explicação parcial dos graus de disseminação social que elas são, hoje, capazes de alcançar: a fisicalidade da música permite o seu maior compartilhamento através da socialização, enquanto a interpretação se abriga no domínio individual. Isso traz conseqüências para as suas respectivas potências de produção de subjetividade, conforme veremos.

Nosso trajeto terá algumas escalas. Caracterizaremos inicialmente o "arrastar" da música, em sua interconexão entre a sensorialidade e a formação localizada de coletividades. $\mathrm{O}$ medievalista Paul Zumthor será o nosso primeiro interlocutor, seguido por Hans Ulrich Gumbrecht - cujo conceito de "presença" estabelece uma plena legitimação estética, política e epistemológica da experiência puramente sensorial. Temos razões, porém, para acreditar que mesmo a experiência sensorial é perpassada por componentes semânticos: com George Lakoff veremos que alguma semântica, ainda que mínima, participa da percepção sensorial - uma semântica ativada de maneira a-consciente, e que portanto não se confunde com a ação interpretativa. Se isso já basta para sugerir que as experiências da música e da literatura não estão radicalmente apartadas entre si, o diálogo seguinte com Wolfgang Iser nos levará a uma teoria que pensa a interpretação como uma ação espontânea, cognitivamente determinada e antropologicamente orientada. Em Lakoff (que localiza a semântica na percepção sensorial) e em Iser (que dissocia a interpretação da hermenêutica), teremos bons apoios para investigar as diferenças estéticas e as possibilidades políticas da música e da literatura, admitindo o "triunfo da música" e ao mesmo tempo preservando um lugar fecundo para a literatura - que, entendida como instância de construção de realidades alternativas a serem experienciadas pelo leitor, tem nisso a sua potência de produção de subjetividade.

Isso encerra os objetivos gerais deste artigo, mas ele estaria incompleto se as próprias noções de política e de subjetivação não fossem debatidas. Para tanto, faremos um recuo no tempo e observaremos o modo pelo qual o pensamento moral e político tratou a sensorialidade da música. Historicamente, ele estabeleceu uma dicotomia entre a pura sensualidade (ou hedonismo) e o significado (o conteúdo) que confere a uma obra o seu status social preciso. Toda abertura à aleatoriedade da resposta individual contraria a crítica moral, e por isso é polêmico, ainda hoje, discutir democraticamente a emergência do político nos processos sociais difusos de formação de subjetividade. Mas é isso o que faremos, num diálogo com a descrição da democracia por Gilles Lipovestski - que a toma como o universo social composto por uma pletora de apelos (informações, pessoas, 
mercadorias, opiniões, valores, na multiplicação das escolhas e na redução das fidelidades) provocadores de respostas que são, em si, a própria formação da subjetividade: nesse meio encontrase o lugar da arte como fonte de estímulo à diferenciação individual. A "democracia" situa numa ambiência sócio-histórica precisa, pois, as experiências atuais da música e da literatura como forças de subjetivação.

Numa tal ambiência, o político emerge individualmente. É em meio às disposições de um self lançado em invólucros sociais flexíveis que a arte se torna politicamente transformadora: ela forma a subjetividade não como uma extensão da política institucional, mas como (no vocabulário de Deleuze e Guattari) uma potência de desterritoralização, escapando ao autocontrole e à consciência-de-si do indivíduo. O caráter a-consciente da experiência estética é o que arrasta o indivíduo a algo inesperado - com a teorização deste processo de subjetivação, fecharemos a comparação das experiências da música e da literatura, em suas conseqüências para os lugares sociais que hoje elas ocupam. Ao fim e ao cabo, o nosso maior objetivo é o de tecer referências estáveis para a observação do estado atual das duas artes, distinguindo os tipos de experiência e os modos de subjetivação que elas mais recorrentemente fomentam. Em meio à presença difusa da literatura e da música na sociedade contemporânea, estabilizar algum referencial analítico pode nos ajudar a observar as suas posições relativas e as suas transformações sucessivas.

\section{Sensorialidade e semântica}

O que nos diz Paul Zumthor (1990, 2001) sobre a poesia oral, e o que ela nos diz sobre as diferenças entre a música e a literatura? Zumthor nos diz que a poesia oral é produzida para ser enunciada (como no cordel e no repente brasileiros), e não para ser lida. Ela não se comporta como texto, integrando uma performance na qual ela é enunciada por uma voz que jamais atua como um meio neutro para a comunicação de conteúdos: para Zumthor, a voz seria uma coisa, às suas qualidades materiais (tom, timbre, volume) sendo assinalados valores simbólicos culturalmente inscritos. Em sua plenitude própria, a voz fala a si mesma no momento em que se enuncia e, por ela, na concretude do contato com o público, a performance revolve saberes compartilhados coletivamente: o reconhecimento produzido pela voz apela a um patrimônio comum de crenças, hábitos mentais, mitos, estórias...

No século XVIII - com o divórcio entre os saberes, o gosto e a retórica da classe alta e as manifestações daquela cultura que, a partir de então, passou-se a chamar de "popular" - a importância social da performance seria obliterada. $\mathrm{O}$ avanço da 
cultura letrada relegaria a performance a um nível inferior da cultura, mas Zumthor insiste que a oralidade continuou viva, tendo finalmente passado a predominar (em consórcio com a visualidade) na cultura contemporânea. Aí a teoria da poesia oral de Zumthor se torna elucidativa da música atual, em especial com o seu conceito de "sociocorporeidade", i.e.: a "coleção de características formais" resultantes da existência de um grupo social, de um lado, e da "presença e natureza sensorial" do corpo do performer. (ZUMTHOR, 2005, p. 62) O corpo - como o do cantor que se movimenta no palco - seria, ele mesmo, uma manifestação da coletividade, produzindo "reações emocionais" coletivas. $\mathrm{Na}$ fisicalidade do contato entre o performer e o público, ambos interagem para produzir, durante a performance, uma coletividade que "se destaca do continuo da existência social" sem dela se dissociar: o local da performance é "destacado do 'território' do grupo" ao mesmo tempo em que é sentido e percebido à luz desta separação, adquirindo sentido apenas a partir dela. Nesta descrição da constituição, pela performance, de um espaço social paralelo, não se teria um bom retrato da circulação social da música popular contemporânea? Por "debaixo" ou "ao lado" da cultura letrada, a oralidade teria prosseguido uma trajetória autônoma à cultura "superior", para readquirir, hoje, um lugar majoritário.

Em eventos como a performance localizamos o "arrastar" próprio à experiência musical. A voz é um factum sensorial que revolve fundamentos sociais consistentes, intervindo nas disposições de indivíduos e grupos de forma $a$-consciente, i.e. à revelia da racionalização, do controle ou da apercepção das subjetividades envolvidas. A voz não aciona a interpretação; no seu "arrastar", a sua pura sonoridade é mais importante do que o próprio significado das palavras enunciadas, que frequentemente não são sequer objeto da atenção do ouvinte. Ao mesmo tempo, o impacto social desta força sensorial ocorre mediante certa codificação que, mesmo não sendo objeto de reflexão, revolve um fundamento semântico que é, como tal, interpretável, o que talvez fique mais claro no fracasso do que no sucesso da comunicação entre performer e público: o fracasso parece sempre suscitar "explicações", "críticas", "comparações"... Sob este abrigo "cripto-semântico", a força da fisicalidade é cara à nossa discussão. Anos mais tarde, Hans Ulrich Gumbrecht radicalizaria o afastamento de Zumthor dos paradigmas do "texto" e da interpretação ao teorizar a experiência estética puramente sensorial: pelo seu conceito de "presença", o "arrastar", que não se presta a nenhuma função ou objetivo maior, seria plenamente legitimado como forma de experiência. Sobrevoemos o seu trabalho sobre as "materialidades da comunicação", ensaiada como um novo paradigma de apreciação do fenômeno estético. As "materialidades" seriam as condições que contribuem para a produção do significado sem serem, elas mesmas, significado; por elas, tratava-se de "tematizar 
o significante sem necessariamente associá-lo ao significado". No final da década de 1980, havia nisso uma rejeição à supremacia institucional da hermenêutica e suas quatro premissas fundamentais: 1) a noção de que o sentido se origina do sujeito e não das propriedades do objeto; 2 ) de que corpo e "espírito" são essencialmente diferentes; 3 ) de que o "espírito" conduz o processo de apreensão do sentido, processo para o qual 4) o corpo é um "instrumento secundário". A interpretação seria uma forma "superior" de relação com o mundo, mas Gumbrecht sugeria que já Heidegger teria rompido com a sua primazia: para Heidegger, "os fenômenos se revelam em sua verdade a partir de um estado de "relaxamento"' que "nada tem que ver com o trabalho intelectual", mas sim com o "permanecer passivo, sem forçar ou apressar a verdade, permitindo que os objetos se revelem em seu ser autêntico" (GUMBRECHT, 1998, p. 142). Na contramão da hermenêutica, certa desatenção seria, para Heidegger, imprescindível para a apreensão da coisa, que se revelaria em sua plenitude apenas para quem não estivesse a buscá-la.

Bloquearia também a centralidade da interpretação o reconhecimento pela lingüística (com Hjelmslev) de uma dimensão da expressão irredutível à fixação semântica, o que permitia abordar o significante em sua força própria: "não mais identificar o sentido, para logo resgatá-lo; porém, indagar das condições de possibilidade de emergência das estruturas de sentido" (GUMBRECHT, 1998, p. 147). Tais "estruturas" confeririam possibilidade ao sentido sem determiná-lo a priori: elas limitariam os seus modos possíveis de acontecimento sem restringi-los a um plano preestabelecido, determinando-o $e$ preservando a sua imprevisibilidade. Deixava-se em aberto, com isso, o "preenchimento" que a "estrutura de sentido" receberia: a atribuição de significado cabe à contingência da situação; diante da sua imprevisibilidade, centrava-se o interesse na "estrutura de sentido", em sua pulsação própria.

Em tal "estrutura", a "materialidade" seria a substância semioticamente não formada (como o concreto na arquitetura) que vale como um fato pleno em si mesmo, subsistindo à interpretação que dela se faça: som, cor, tato, ela é discernida como forma. O impacto da música teria esta origem material, física, e portanto alheia à estabilização interpretativa. No momento rápido da audição, no freqüente estado de semi-desatenção em que ela ocorre, a eclosão da "presença" decorreria da percepção da emergência súbita de uma forma nova, cuja factualidade não demandaria o suplemento da interpretação - ela seria a factualidade da apreensão súbita da coisa ela-mesma. A "presença" seria, assim, um evento corpóreo: ela é a percepção da novidade da forma que, em seu aparecimento, altera o funcionamento das nossas funções corporais, colocando-nos física e mentalmente em conexão com o fenômeno. 
Resta saber, porém, se uma experiência sensorial pode ser de fato desprovida de elementos semânticos. Certo vínculo entre a semântica e a sensorialidade foi antecipado pelo próprio Gumbrecht, ao falar da "oscilação" entre uma e outra na experiência da arte (GUMBRECHT 2004). Mas talvez haja mais do que oscilação: talvez haja simultaneidade. Por exemplo, ao falar sobre a surpresa formal do evento atlético - a ocupação inesperada do espaço por corpos em movimento imprevisível, porém ordenado -, Gumbrecht o descreve como "uma epifania da forma", porque ele tem sua substância nos corpos dos atletas envolvidos, porque a forma que ele produz é improvável e porque é uma forma temporalizada, que começa a desaparecer no exato momento em que aparece. (GUMBRECHT, 2006) Com o termo "epifania", Gumbrecht quer descrever o impacto provocado pelo rápido aparecimento e desaparecimento de um evento singular e irrepetível - mas não demandaria isso algum investimento semântico? O próprio termo "epifania" tem uma conotação positiva, que combina bem com a felicidade da arquibancada diante do drible: mas que o drible seja ao mesmo tempo "bom" e "belo", isso não indica uma valoração que, como tal, tem que ser semantizada, ainda que de modo infraconsciente? E se há alguma semântica envolvida na "presença", pode-se falar em pura sensorialidade?

No final dos anos 80, enquanto Gumbrecht teorizava o campo não-hermenêutico, o lingüista George Lakoff (1987) propunha que mesmo o percepta captado visualmente, sem a mediação do significado, é organizado como forma através de categorias. A organização espacial dos fenômenos obedeceria a molduras cognitivas sintetizadas em categorias mentais como as de "centro-periferia", "continente-conteúdo", "frente-verso", "parte-todo", "conexão" ou "objetivo". Nossa percepção visual nunca seria puramente sensorial, porquanto organizada por categorias relacionais que o observador aplica espontaneamente aos fenômenos, daí organizando a forma. Isso é afirmar que os sentidos são biológica $e$ cognitivamente estruturados, e por isso conseguem organizar os fatos da experiência de forma relacional sem, para tanto, recorrer à razão. Sob esta teoria, a "epifania" de Gumbrecht seria ao mesmo tempo corpórea e semântica.

Nesta indissociação entre a semântica e a percepção, categorias mentais como as de "conexão" ou de "objetivo" colocariam a base semântica mínima a permitir que o movimento de um atleta seja associado a atributos como "sucesso" ou "fracasso". A "epifania" estaria vinculada ao juízo, mas um juízo que não demanda o trabalho da razão. A semântica imanente às categorias mentais não seria externa, mas sim interna à percepção: ao invés de representar o significado numa estrutura simbólica, segundo Lakoff a percepção incorpora o significado, organizando espontaneamente o sentido. Por isso o espectador sente uma jogada como 
boa, sem precisar formular tal julgamento. Entre a semântica e a corporeidade não haveria incompatibilidade, pois a reação corporal ativaria a semântica sem demandar a sua racionalização.

Isso volta a localizar um componente semântico no "arrastar" musical. Vimos que Zumthor associava o "arrastar" da voz e da performance à sua ação sobre fundamentos coletivos que, como tais, são necessariamente semantizados. Em Lakoff, a própria sensorialidade é organizada por padrões semânticos espontaneamente ativados. Daí, tomando a literatura como foco, é oportuno ver como Wolfgang Iser teorizou a leitura como um estímulo a uma interpretação espontânea, motivada pela demanda, de cunho antropológico, que temos pelas artes que, ao nos possibilitarem experienciar realidades paralelas à realidade vivida, nos revelam algo sobre nós mesmos.

Ao tratar a interpretação como uma ação espontânea, Iser afirmava que o sentido emerge da leitura do texto, não coincidindo nem com a imanência do texto nem com as projeções do leitor. O sentido estaria na dobra entre o texto e a projeção, no imaginário do leitor, de algo que não coincide com o texto, mas que é por ele possibilitado: as inscrições do texto fazem surgir, na mente do leitor, algo que é projetado pelo texto mas que dele se diferencia enquanto projeção mental. Com isso, a experiência do texto dá origem ao imprevisto, a leitura sendo um fenômeno radicalmente individual: ela é o encontro entre a obra e o leitor em sua contingência histórica, social e individual precisa. Ao transcender as especificidades do texto que o motiva, o efeito estético encontraria na surpresa - na novidade - a sua força de perspectivização do "mundo", nisso residindo o poder da literatura como instância de produção de subjetividade. Portanto, se a literatura não se dissemina como a música, ela produz efeitos de outro tipo: a experiência, pelo leitor, de "realidades ficcionais" - não submetidas às pressões da realidade vivida faz da literatura uma instância de "construção de mundo" - um mundo que emerge, no leitor, imaginativamente. Esta vivência de realidades alternativas coloca as disposições pessoais do leitor (seus afetos, expectativas, pré-conceitos, valores, opiniões) sob uma orientação que, não-pragmática, permite uma resposta exploratória, alheia à rapidez do cotidiano. Ao revolver estas disposições subjetivas, a literatura se torna uma potência de subjetivação, mediada por uma interpretação que, instantânea, impacta o leitor à revelia da sua apercepção e autocontrole (algo próxima, portanto, do "arrastar" da música e da performance). À sua maneira, também a literatura nos "arrasta" a algo outro, exercendo assim o seu poder de diferenciação - a sua potencial força de pragmatização política.

Comparativamente, pois, enquanto a música - mesmo em sua sensorialidade - parece comportar elementos semânticos que colaboram para o tipo de diferenciação subjetiva que 
a experiência estética fomenta, a interpretação do texto não parece demandar a racionalização - a reflexão - que o termo "interpretação" ordinariamente sugere, podendo transcorrer numa rapidez semelhante à do "arrastar" musical. Nalguma medida, esta comparação sugere semelhanças entre a música e a literatura; ao mesmo tempo, porém, ela não basta para eliminar a maior sedução que música é capaz de exercer: ainda que quaseinstantânea, a interpretação do texto literário ainda demanda o retraimento silencioso da leitura, que em tudo contrasta com o poder da música em alcançar, e de fato provocar esteticamente, inúmeras pessoas em inúmeros momentos das suas rotinas - no trânsito, no comércio, nas ruas...

\section{Legitimação política da arte; "democracia" e política como "emergência"}

Pela somatória de Zumthor, Gumbrecht, Lakoff e Iser, o impacto da arte sobre o self se dá entre o corpo, a linguagem e a consciência; a partir desta perspectiva, podemos falar sobre as condições sociais em que a arte é lançada, hoje, como instância (eventualmente política) de formação de subjetividade: se a diferenciação da subjetividade pela arte pode ocorrer sem o recurso à racionalização, e se isso pode ser suscitado mesmo pela experiência sensorial, podemos pensar, a partir disso, os limites e poderes específicos que a música e a literatura encontram na sociedade atual. Para tanto, é preciso dissociar a teorização política da arte da legislação moral a que ela foi historicamente submetida - em especial porque a sensorialidade nos coloca diante de uma legitimação política da arte pela qual a sua participação na autoprodução social é dissociada da ideia de "melhoramento". Não é que a coletividade não participe da sensorialidade: por ela apenas não se obedece à política como ação programática.

O "arrastar" é uma diferenciação a-consciente que destaca o indivíduo do seu contínuo de vida, levando-o, pelo menos momentaneamente, a algum lugar outro. Para certa fração do pensamento moral, o apelo sensorial da música a tornaria perigosa: enquanto o significado do texto pode ser estabilizado pelos agentes (o crítico, o docente...) que orientam a sua difusão social, a música parece incontrolável; historicamente, o pensamento moral tomou a sua sensualidade como uma potência de desvio. Ela tiraria o indivíduo dos "estados ideais" de atenção, conduta social e mobilização ético-política postulados normativamente, adulando os sentidos e sabotando a razão, e sendo por isso rebelde à coerção política e ao saber conceitual. Já Platão condenava o impacto da música como veículo de conteúdos políticos, pois ela se "infiltraria" no indivíduo driblando o controle da razão e influenciando-o mimeticamente. A sua solução é 
famosa: controlar a sua forma e o seu conteúdo, autorizando apenas a produção cujas características favorecessem a retidão propícia à "Paidéia". Exemplar no conteúdo, a boa arte deveria ser ascética na forma, a música devendo conciliar o fortalecimento corporal da ginástica à brandura da filosofia: "Aquele que associa com mais beleza a ginástica à música e, com mais tato, as aplica à alma, é músico perfeito. [...] precisaremos também na nossa cidade de um líder capaz de regular esta associação, se quisermos salvar nossa constituição." (PLATÃO, 2000, p. 107) Como mandamento para a produção e critério para a avaliação judicativa, Platão defendia a ascese compositiva como meio de fomento de uma ascese recepcional que, por sua vez, fomentaria a boa conduta política, prevendo uma isonomia perfeita entre as características imanentes da obra e a recepção que ela provoca (o público aparecendo como uma caixa de ressonância).

Vale aí uma comparação com a ascese em Santo Agostinho. Em Confissões, a ética postulada para a realidade intra-mundana queria reger o convívio num cotidiano encharcado do comércio urbano e da sua corrupção, o que levava à necessidade de uma autovigilância asceticamente praticada. Na república ideal de Platão, a vigilância caberia aos líderes, os demais estando imersos em rotinas capazes, por si mesmas, de conferir concretude ao ideal. Em Agostinho, a vigilância era internalizada a cada fiel, que se tornaria responsável pela sua autoobservação. Os fiéis deveriam saber distinguir as práticas boas das ruins, praticando um controle internalizado (pois não há mecanismo coercitivo externo que esteja ativo em todo lugar e a todo instante). No que cabe à música, a ascese, o autocontrole e a autocoação na experiência sensorial fariam a distinção entre a elevação e a frivolidade, tanto na qualidade da composição quanto - e principalmente - na relação que o indivíduo estabelece com ela. $\mathrm{O}$ fiel não pode confiar em si mesmo, pois os espetáculos são por demais poderosos - não foi Alípio tragado pelo circo? Por isso o autocontrole previa a suspeita de si, requisito máximo da vigilância. Na experiência musical, apenas a precedência do conteúdo (no canto em louvor a Deus) sobre a sonoridade poderia garantir a justa medida da composição e da experiência - e Agostinho observa que, "Quando às vezes a música me sensibiliza mais do que as letras que se cantam, confesso com dor que pequei. Neste caso, por castigo, preferiria não ouvir cantar." (SANTO AGOSTINHO, 1988, p. 251) Desse modo, o controle das relações entre aisthesis e atribuição de significado, que em Platão remetia à grande arena política, aparece, em Agostinho, substancializado numa autocoação cotidiana - pois mesmo o bom fiel se pega pecando, e todo pecado revela um conteúdo íntimo de verdade.

A partir de manifestações como estas, em sua longa duração e em suas várias formulações o pensamento moral jamais daria plena autonomia ao juízo privado. A desconfiança de 
si - consagrada em Agostinho - se combinaria de múltiplas maneiras com a autoridade judicativa do crítico - consagrada em Platão -, estabelecendo a "condenação do prazer" que Roland Barthes (2004), ainda em 1973, sentia a necessidade de denunciar. O maior problema para o pensamento moral está na atribuição de autonomia ao indivíduo: à individualização, à subjetivação, à atomização ele opõe a jurisdição, a prescrição, a norma. Como devemos, então, pensar o lugar da arte no mundo atual, que a todo tempo individualiza e privatiza o juízo e a experiência?

A este mundo chamaremos de "democracia". Com este termo, não nos referimos à democracia partidária, que tanto tem desenergizado a ação política. Interessa-nos, isso sim, a acoplagem democrática entre a política, a economia e a comunicação pessoal. Na sua velocidade e imprevisibilidade, forma-se por elas um contínuo social que subtrai dos valores as suas pretensões à verdade, enfraquecendo as fidelidades e os vínculos. $\mathrm{Na}$ produção política das subjetividades, este cenário aumenta a responsabilidade individual pelo juízo, que não se ampara em verdades compartilhadas (pois mesmo os valores se individualizam). Legitima-se uma pluralidade de vozes, numa polifonia constante em que se é continuamente chamado a se posicionar sobre uma infinidade de fatos e temas, multiplicando-se os (pequenos) momentos de formação de subjetividade. Esta massa de pequenos eventos decerto produz redundâncias, tagarelices, sensos comuns - em seu dinamismo, porém, toda reiteração é permeável à diferenciação.

É claro que pesa sobre a democracia o perigo da indiferenciação. As pequenas vozes podem apoiar o enrijecimento; grandes padrões (comportamentais, econômicos, políticos) sempre podem se erguer. Mas há um aumento relativo do poder de autodeterminação do agente histórico comum, uma vez que o "déficit de absoluto" da democracia viabiliza graus variados de autonomia: ao invés de uma autonomia "plena", tem-se um poder localizado de autodeterminação. Estabelece-se um equilíbrio tênue entre o "determinismo absoluto" e a "liberdade metafísica": nem as grandes estruturas determinam in toto as subjetividades, nem nos é possível escapar das suas constrições; trata-se de uma liberdade exercida dentro de códigos e expectativas aos quais os indivíduos estão flexivelmente atrelados. Nada disso é belo: a democracia não traz conciliação, harmonia ou síntese; pelo contrário, ela amplia o ruído. Mas ao legitimar a pequena satisfação, o gozo privado e a fruição do presente, ela aumenta o direito à escolha: talvez o seu resultado mais palpável seja o aumento da complexidade e da imprevisibilidade das movimentações sociais.

Esta apropriação de Lipovetski (2009) admite um otimismo polêmico contra as acusações de "pasteurização" da vida contemporânea. Por ela, podemos passar da dissolução 
da autoridade e das relações de fidelidade para uma descrição dinâmica das movimentações sociais, onde mesmo as solidificações se constituem no processamento caótico das redes sociais, sob a lógica da contingência. Existe certa não-consciência na dinâmica democrática, em sua imprevisibilidade e flexibilidade: os seus movimentos não são objeto de "controle". Há uma movimentação permanente, vagarosa ou acelerada, dos elementos pertencentes ao campo, intervindo nas estruturas que lhe dão a sua consistência própria e destarte modificando-o, transformando-o ou mesmo desfazendo-o operacionalmente. $\mathrm{O}$ acaso determina os acontecimentos em conjunto com as estruturas preexistentes, que são, porém, permeáveis à mudança. Além disso, cada campo subsiste em contato com um ambiente externo que intervém, por atrito, nos seus desdobramentos internos. $\mathrm{O}$ acaso, em sua participação na relação entre a estrutura interna e o ambiente externo, é internalizado à gênese dos acontecimentos: assim descrita, a democracia multiplica as circunstâncias e as possibilidades de formação da subjetividade, também sob a lógica da contingência.

Com isso colocamos sob um prisma social dinâmico as relações entre a arte, a política e a subjetivação. Na experiência da arte, importa observar como o encontro entre um indivíduo (flexivelmente atrelado à coletividade) e uma obra (lançada em meio a um universo de estímulos), ocorrendo num momento (pessoal, histórico, social) preciso e dentro de uma forma precisa de experiência (na leitura solitária, na platéia do teatro, na audiência do concerto, nos corredores do museu...) - importa observar como a somatória destas condições faz emergir, no indivíduo, um efeito político de alguma ordem. Neste prisma, a política perde a sua substância ideológica, sendo entendida como a "desterritorialização" que altera, ainda que minimamente, a relação do self com o mundo imediato: são políticas as "desterritorializações" (das expectativas, dos comportamentos, dos vestuários, das relações sociais) a ocorrer consciente ou inconscientemente. Ao mesmo tempo, a palavra "obra" perde a sua substância normativa, estendendo-se a qualquer objeto artístico, da sinfonia à revista em quadrinhos: quaisquer tipos de objeto podem provocar experiências desterritorializantes. Por fim, o termo "indivíduo" perde a sua substância psicológica: ao invés de preservarmos o fundamento da identidade (como plenitude ou vazio), interessa-nos a emergência da subjetividade a partir da experiência com a arte, o que ocorre à revelia do indivíduo.

Por tudo o que foi dito, o modelo descritivo-explicativo do "rizoma", de Deleuze e Guattari, nos indica um bom caminho para o tratamento do tema. Em sua atribuição de dinâmica à solidez, na indissociação entre a solidificação e a mudança permanente, o "rizoma" - quando aplicado à teoria da subjetividade prevê que o self, em sua história imanente e em seu lançamento às 
trocas sociais, pode se transformar de forma subterrânea ao seu controle consciente e para além das suas próprias cristalizações reiterativas, sendo levado por processos que o conduzem, rápida ou vagarosamente, a novas condições. Nesta rede de interações alocamos a potência transformadora da arte, identificando-a como uma potência política. Em sua defesa da imprevisibilidade, em tal modelo não sabemos, jamais, que arte terá impacto sobre o self ou que impacto será este - a pragmatização política da arte, seja ela boa ou ruim, pode se originar do contato com qualquer arte. Diante de um caso específico - a importância de uma obra para um self - é decisivo inclusive o momento preciso em que obra e self se encontram: o self que somos no momento em que experienciamos (ou reexperienciamos) um objeto é decisivo para a importância que ele terá para nós.

No rizoma, a política adquire uma temporalidade ao mesmo tempo geológica e química. Há o tempo lento da arborescência, que provoca a univocidade do sentido (dos estados macroscopicamente sólidos), mas há também o tempo rápido das "linhas de fuga", pelas quais os estratos se diferenciam. $\mathrm{O}$ rizoma se autodiferencia permanentemente, pois

qualquer ponto [seu] pode ser conectado a qualquer outro e deve sê-lo. [...] cadeias semióticas de toda natureza são aí conectadas a modos de codificação muito diversos, cadeias biológicas, políticas, econômicas, etc., colocando em jogo não somente regimes de signos diferentes, mas também estatutos de estados de coisas. [...] não se pode estabelecer um corte radical entre os regimes de signos e seus objetos. (DELEUZE e GUATTARI, 1995, p. 15)

Objetos e signos se determinam reciprocamente em agenciamentos complexos, fazendo com que o sistema jamais seja idêntico a si mesmo - pois ele é perpassado pela autodiferenciação constante. Este processo não pressupõe a atuação de um "sujeito": a diferença é imanente à repetição, que é, por sua vez, diferenciadora; rizomas podem levar à produção de nódulos que se fixarão no tempo, mas a fixidez é perpassada por linhas de fuga que a desestabilizam. Permeando a solidez da "árvore", o rizoma é a pulsação das interconexões: por ele as coisas e os atributos das coisas atravessam. Por isso tal modelo descreve bem a complexidade do pertencimento da arte a uma vida: ao atravessar hábitos, costumes, práticas, obrigações, a arte integra ou diferencia o contínuo da vida, de maneira mais ou menos notável. Em qualquer caso, "a arte nunca é um fim, é apenas um instrumento para traçar as linhas de vida, isto é, [todas] essas desterritorializações positivas, que não irão se reterritorializar na arte, mas que irão [...] arrastá-la consigo para as regiões do a-significante, do a-subjetivo e do sem-rosto." (DELEUZE e GUATTARI, 1996, p. 57) 
Este arrastar ("a-significante, a-subjetivo e sem-rosto") é o que nos interessa: ao nos estimular a-conscientemente, a arte pode alterar as recorrências que estabilizam as relações de uma subjetividade com o mundo. Tais recorrências envolvem inúmeras coisas; socialmente, a subjetividade é um "conjunto das condições que torna possível que instâncias individuais e/ou coletivas estejam em posição de emergir como território existencial auto-referencial, em adjacência ou em relação de delimitação com uma alteridade ela mesma subjetiva." (GUATTARI, 1992, p. 19) Um complexo de estímulos (midiáticos, econômicos, lingüísticos etc.) constitui a rede dentro da qual a subjetividade se forma e vai se transformando, em conjunto com a transformação da própria rede. Estes processos não são planejáveis ou previsíveis, pois não podem ser conhecidos "através de representações[,] mas por contaminação afetiva. Eles se põem a existir em você, apesar de você." (GUATTARI, 1992, p. 117) É por isso que nada está totalmente dado, previsto ou controlado, ainda que o juízo tente congelar as coisas, as pessoas, os enunciados, os lugares e as condições de enunciação, instituindo um sistema estável de atribuições - como aquele que tentou aprisionar a música dentro de certos modelos de conduta, em Platão e em Agostinho.

\section{Coda}

Conforme antecipamos na apresentação deste ensaio, parte fundamental do nosso objetivo estava em buscar parâmetros para a apreciação das diferenças entre a música e a literatura, distinguindo os modos de experiência e de subjetivação que elas favorecem. Sem que tivéssemos pretensão à exaustividade, a aposta era a de que tais parâmetros ajudassem a situar as posições das duas artes na sociedade contemporânea, em suas flutuações incessantes.

Sintetizemos o percurso cumprido. Ao situarmos a arte na realidade dinâmica e imprevisível que chamamos de "democracia", nela compreendendo a arte como uma potência (ocasionalmente política) de subjetivação, definimos a experiência estética como um encontro (circunstancial, ainda que posteriormente repetível) entre os indivíduos (isolados ou em conjunto) e os fatos artísticos (sejam eles "obras" ou não). Sob as várias formas socialmente disponíveis de experiência da arte (e de tantas que vão sendo criadas, como a instalação ou, mais recentemente, a poesia virtual), tal encontro pode produzir algum tipo de diferenciação, a priori imprevisível. É por isso que, neste modelo, a política perde a sua substância ideológica: se aquela diferenciação altera, em especial, a nossa relação com o mundo imediato, isso não está relacionado, a priori, com qualquer conteúdo político-institucional preciso. Eventuais desvios de expectativas, de comportamentos, de relações sociais, de vestuários são tão 
políticos quanto a ideologia sistematizada - além de mais freqüentes e mais claramente atribuíveis à experiência da arte.

Tais desvios podem ocorrer consciente ou inconscientemente: a autoconsciência não é necessária à diferenciação produzida pela arte, ainda que ela possa participar do processo. Em todo caso, o termo "indivíduo" perde, para as nossas finalidades, a sua substância psicológica, pois a consciência-de-si (e a identidade) cede passagem à emergência da subjetividade na experiência com a arte. Da mesma maneira, a palavra "obra" perde a sua substância normativa, passando a abranger qualquer tipo de objeto: não há como prever quais objetos provocarão experiências desterritorializantes em indivíduos ou grupos específicos. Tomada de empréstimo de Deleuze e Guattari, esta é uma teoria da subjetividade como uma teoria da emergência da subjetivação a partir da experiência - teoria à qual recorremos após termos debatido a oscilação entre a semântica e a sensorialidade na experiência da arte.

Falar sobre a polarização semântica-sensorialidade obedeceu a um problema epistemológico: com o pêndulo vincado em Gumbrecht e a sua teorização da experiência estética sensorial, procuramos mostrar, em direção algo divergente do próprio Gumbrecht, que semântica não é sinônimo de interpretação, podendo se localizar na ação instantânea e não-refletida da performance sobre fundamentos sociais coletivos (como em Zumthor), na ainda menos refletida semantização da percepção sensorial (em Lakoff), ou ainda (em Iser) na leitura como um ato no qual interpretação transcorre numa rapidez próxima àquela da experiência sensorial. Encontrar um balanço harmonioso entre a rapidez e a irreflexão da sensorialidade e a (comparativa) lentidão e a autoconsciência da interpretação foi o caminho escolhido para pensarmos tanto o modo pelo qual a sensorialidade pode (apesar do seu pouco estímulo à reflexão) provocar diferenciações subjetivas mais consistentes do que a mera "sedução" que Platão e Agostinho criticavam, quanto o modo pelo qual a interpretação preserva um componente dinâmico que permanece, afinal, afim à rapidez das trocas que compõem o mundo atual. Em meio a esta problemática, procuramos nos dissociar da crítica moral que ainda subtrai à experiência sensorial a sua plena legitimidade social.

No pêndulo entre a semântica e a sensorialidade, entre a aisthesis e a interpretação, entre a irreflexão e a consciência, a música e a literatura oscilam entre um pólo e outro: não há distinção clara e cortante entre as experiências das duas artes, em si mesmas variadas; toda generalização pressupõe alguma dose de tipificação. Em linhas gerais, porém, se a literatura é de incidência majoritariamente individualizada - em contraste com a recepção potencialmente mais coletiva da música - fica claro que os seus lugares sociais são determinados pelos tipos 
de experiência que elas favorecem: com a dimensão pública que a música assumiu no século $X X$, vê-se que não apenas as suas presenças sociais, mas também as suas atuações como instâncias de diferenciação política e de produção de subjetividade se diferenciaram. Neste artigo, pretendemos ter colocado termos que, generalizantes, ajudem a operacionalizar a observação destas questões. A partir deles, cada evento específico revelará a sua singularidade.

\section{Abstract}

The article debates the contemporary conditions of the relationship between politics and the production of subjectivity in music and literature, from two precise angles: 1) the differences between the types of aesthetic experience that the two arts stimulate; 2) the actualization of these experiences in the current condition of art's social dissemination. From the contribution of authors from the Literary Studies (Zumthor, Iser, Gumbrecht) and philosophy (Deleuze, Guattari, Lipovetski), among other fields, the article discusses the contrast between the sensoriality of music and literature's call for interpretation, from which it derives 1) the reasons for the differences the social disseminations of one and the other, 2) the differences between music and literature as stances of production of subjectivity. In this last item music is described as a force that subjectifies the individual by "dragging" him to a different position regardless of his conscious control, whereas literature provides the experience of alternative realities to those of everyday life. By affirming the legitimacy of these two processes of subjectification, the sensorial aesthetic experience is rescued from the moral critique to which it was historically submitted, as it acquires (together with the interpretive kinds of aesthetic experience) a politically productive domain within the current (democratic) conditions of information exchange. As a general goal - based on typological comparisons between the two arts - the article tries to establish a descriptive analytical framework for the observation of their presences and relative positions in contemporary society.

Keywords: literature; music; politics; subjetivity; aesthetic experience. 


\section{REFERÊNCIAS}

BARTHES, Roland. O prazer do texto. São Paulo: Perspectiva, 2004. BLANNING, Tim. O triunfo da música. São Paulo: Companhia das Letras, 2011.

DELEUZE, Gilles; GUATTARI, Félix. Mil platôs, vol. 1. Rio de Janeiro: Ed. 34, 1995. Mil platôs, vol. 3. Rio de Janeiro: Ed. 34, 1996.

GUATTARI, Félix. Caosmose. Um novo paradigma estético. São Paulo: Ed. 34, 1992.

GUMBRECHT, Hans Ulrich. "O campo não-hermenêutico ou a materialidade da comunicação". In: Corpo e forma. Rio de Janeiro: EdUERJ, 1998, pp. 137-151.

. Production of presence - what meaning cannot convey. Stanford: Stanford University Press, 2004.

Press, 2006.

. In praise of athletic beauty. Cambridge: Harvard University

ISER, Wolfgang. O ato da leitura, vol. 1. Rio de Janeiro: Ed. 34, 1996a.

O fictício e o imaginário: perspectivas de uma antropologia literária. Rio de Janeiro: EdUERJ, $1996 b$.

LAKOFF, George. Women, Fire, and Dangerous Things. Chicago: University of Chicago Press, 1987.

LIPOVETSKY, Gilles. O império do efêmero. São Paulo: Companhia de Bolso, 2009.

PLATÃO. A república. São Paulo: Nova Cultural, 2000.

SANTO AGOSTINHO. Confissões. Petrópolis: Vozes, 1988.

ZUMTHOR, Paul. Oral poetry: an introduction. Minneapolis: The University of Minnesota Press, 1990.

A letra e a voz - a "literatura" medieval. São Paulo:

Companhia das Letras, 2001.

. Escritura e nomadismo. Cotia: Ateliê Editorial, 2005. 